\title{
AKURASI METODE RADIOKOLLOID DAN BLUE DYE DALAM MENDETEKSI LIMFONODI SENTINEL PADA KANKER PAYUDARA STADIUM DINI
}

\section{THE ACCURACY OF RADIOCOLLOID AND BLUE DYE METHODS IN DETECTING SENTINEL NODE IN THE EARLY STAGE OF BREAST CANCER}

\author{
Yuyun Yueniwati*, N. Diana Yulisa**, Arief Iskandar \\ * Laboratorium / SMF Radiologi Fakultas Kedokteran Universitas Brawijaya / RSU dr. Saiful Anwar Malang \\ ** Laboratorium Radiologi / SMF Fakultas Kedokteran Universitas Indonesia / RSU dr. Cipto Mangunkusumo Jakarta
}

\begin{abstract}
Breast cancer incidence varies in many countries but in general increases. This research aimed to find out the accuracy of radiocolloid (lymphoscintigraphy and gamma probe) as well as blue dye method in detecting sentinel node in the early stage breast cancer. Diagnostic examination was conducted on 163 nodes of 14 patients cross sectionally, comparing the accuracy of radiocolloid and blue dye methods with histopathologic method as the gold standard. Subject characteristics were female, aged 39-53, mostly menopause, multipara and breast-feeding. Primary tumors were mostly found in the right, upper lateral quadrant, T2, histopathologic results showed that all were of invasive ductal carcinomas and $71.4 \%$ cases were lymphatic emboli. The detection of sentinel node with lymphoscintigraphy had $81.8 \%$ accuracy, sensitivity 90.4\%, specificity $73.2 \%$, NPV 98.1\%, false-negative 1.8\% and kappa value 0.37. Detection using gamma probe resulted in $79 \%$ accuracy, sensitivity $90.4 \%$, specificity $67.6 \%$, NPV 97.9\%, false-negative $2 \%$ and kappa value 0.31 . When both were conducted, it had $83.6 \%$ accuracy, sensitivity $90.4 \%$, specificity $76.8 \%$, NPV 98.2\%, false-negative $1.8 \%$ and kappa value 0.56 . Fourteen percen sentinel node were internal mammary node. The accuracy of blue dye method cannot be calculated in this research, detection rate was $71.4 \%$. It is concluded that radiocolloid method has high accuracy and suitability in detecting sentinel node in the early stage of breast cancer, and can be applied for early detection in conjunction with Sentinel Lymph Node Biopsy (SLNB).
\end{abstract}

Key words: radiocolloid, blue dye, sentinel node, breast cancer

\section{PENDAHULUAN}

Angka kejadian kanker payudara bervariasi di tiap negara, akan tetapi secara umum terus menunjukkan peningkatan (1-8). Di negara-negara berkembang kanker payudara menempati urutan pertama dan merupakan penyebab kematian utama akibat kanker pada perempuan (1-4). Di Indonesia kanker payudara merupakan keganasan kedua terbanyak setelah kanker serviks uteri (1).

Perkembangan dalam bidang radiologi, bedah, dan onkologi menyebabkan perubahan dalam diagnosis, penatalaksanaan, dan prognosis kanker payudara (2-4). Meningkatnya kesadaran terhadap gejala dini dan adanya program skrining menyebabkan angka kejadian kanker payudara stadium dini meningkat sedangkan angka kejadian stadium lanjut menurun (1-3).

Terjadi revolusi penatalaksanaan pembedahan kanker payudara seiring dengan perkembangan radioterapi, kemoterapi, dan terapi hormonal, dengan tujuan mendapatkan kontrol lokoregional yang baik, angka ketahanan hidup

Jurnal Kedokteran Brawijaya,Vol. XXIII, No. 1, April 2007 Korespondensi: Yuyun Yueniwati; Lab / SMF Radiologi FK Unibraw /RSU dr. Saiful Anwar; Jl. Jaksa Agung Suprapto No. 2 Malang; Telp. 0341-362101, email: yyueniwati@yahoo.com yang tinggi serta komplikasi tindakan seminimal mungkin. Pada akhir abad 19 dilakukan mastektomi radikal klasik (Halsted) dan mastektomi modifikasi (Patey atau Madden) yang terbukti memberikan kontrol lokoregional dan angka ketahanan hidup yang baik. Namun cara ini tidak nyaman bagi pasien karena menyebabkan deformitas dada serta gangguan pergerakan leher dan bahu, kehilangan payudara juga memberikan dampak psikologis yang tidak menyenangkan bagi pasien (1)

Pada tahun 1971 Bernard dan Fisher memperkenalkan teknik baru Breast Conserving Treatment (BCT) pada kanker payudara stadium dini. BCT terdiri dari eksisi luas lokal terbatas atau segmentektomi/ kuadranektomi disertai diseksi aksila dan radioterapi (1-5). Teknik ini mulai dilakukan di Jakarta tahun 1982 (1). Dengan BCT bentuk payudara dapat dipertahankan tetapi diseksi aksila menimbulkan banyak keluhan seperti nyeri, keterbatasan pergerakan bahu, rasa baal, pembentukan seroma, limfedema, dan alasan kosmetik (3). Beberapa tahun terakhir dilaporkan hasil diseksi limfonodi pada kanker payudara stadium dini tidak menunjukkan adanya metastasis, sehingga metode diseksi aksila konvensional mulai diperdebatkan (4). Pada pertengahan tahun 1990-an mulai dilakukan teknik baru yang lebih tidak invasif pada penatalaksanaan kanker payudara, yaitu 
Sentinel Lymph Node Biopsy (SLNB) (2-6) Limfonodi sentinel pada kanker payudara didefinisikan sebagai satu atau lebih limfonodi yang kemungkinan besar terjadi drainase limfatik dan metastasis (3). Secara teori teknik SLNB dapat memprediksi status aksila dan sangat potensial mengurangi morbiditas akibat diseksi aksila (2-7) Metastasis ke limfonodi aksila merupakan faktor prognostik utama yang penting pada kanker payudara sehingga menjadi dasar penatalaksanaan (4-7). Beberapa penelitian menunjukkan SLNB mempunyai angka prediksi tinggi terhadap status limfonodi aksila dengan hasil negatif palsu kurang dari $5 \%$ sehingga SLNB dipercaya merupakan teknik pengganti diseksi aksila konvensional (1-5).

Deteksi limfonodi sentinel mempunyai peranan yang sangat penting dalam SLNB. Ada dua metode yang umum digunakan, yaitu menggunakan metode radiokolloid (limfoskintigrafi $\mathrm{Tc}^{99}$ colloid preoperasi dan gamma probe intraoperasi) dan metode blue dye (2-24). Akurasi deteksi limfonodi sentinel menggunakan radiokoloid $82 \%$, menggunakan blue dye $66 \%$, apabila dilakukan kombinasi akurasinya mencapai $92 \%$ (8). Sampai saat ini belum ada data akurasi metode radiokolloid dan blue dye di Indonesia.

Di Indonesia SLNB belum menjadi prosedur tetap penatalaksanaan kanker payudara stadium dini. Penelitian ini dilakukan untuk mengetahui akurasi metode radiokolloid dan blue dye dalam mendeteksi limfonodi sentinel pada kanker payudara stadium dini di RS Ciptomangunkusumo Jakarta yang pada akhirnya akan menentukan stadium dan penatalaksanaan kanker payudara secara umum.

\section{METODE}

Penelitian ini merupakan uji diagnostik secara cross sectional, dilakukan di Kedokteran Nuklir dan Instalasi Bedah Pusat (IBP) RSCM Jakarta. Berlangsung dari bulan Januari sampai Juni 2006. Populasi terjangkau adalah semua pasien kanker payudara TX-T1-T2 (TNM System), No, MO, yang bila perempuan tidak sedang hamil atau menyusui, tidak alergi terhadap radiofarmaka nanocolloid, dan blue dye, serta bersedia menjadi sampel penelitian. Besar sampel dihitung menggunakan tingkat kemaknaan ( $\alpha$ ) $5 \%$ dan tingkat ketepatan absolut (d) yang dikehendaki $10 \%$. Berdasarkan perhitungan, jumlah sampel minimal yang dibutuhkan 150 limfonodi. Penelitian dilakukan setelah mendapat informed consent dari subyek penelitian.

Deteksi limfonodi sentinel dengan metode radiokolloid meliputi pemeriksaan limfoskintigrafi preoperasi dan gamma probe intraoperasi. Pemeriksaan limfoskintigrafi preoperasi dilakukan dengan menyuntikan technetium $\left(\mathrm{TC}^{99}\right)$ colloidal rhenium sulphide (nanocolloid) $2 \mathrm{mCi} / 2 \mathrm{cc}$ subkutan 4 kuadran pada T1 dan T2, dan 2 mCi/1 cc intrakutan di 2 sisi bekas incisi minimal 2 tempat tergantung luas incisi pada TX. Kemudian dilakukan pemeriksaan gambaran dinamik 45 menit setelah penyuntikan, statik awal 1 jam se- telah penyuntikan, dan statik lambat 1 jam sebelum operasi dengan alat Sophy camera tahun 1994 double head dengan kolimator energi rendah resolusi tinggi. Hasil positif bila terdapat aktivitas radiofarmaka pada limfonodi / hot node.

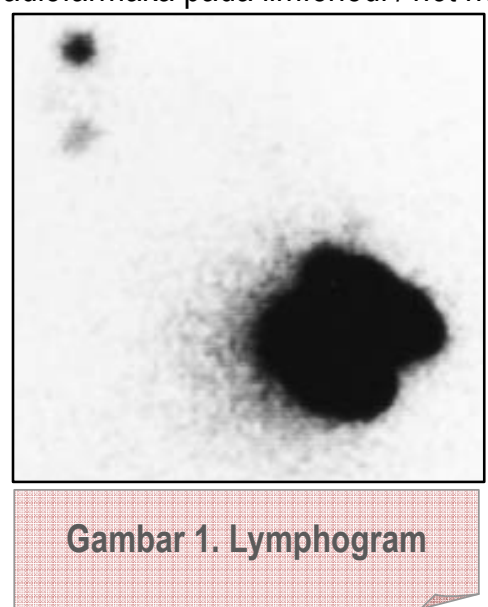

Pemeriksaan menggunakan gamma probe dilakukan

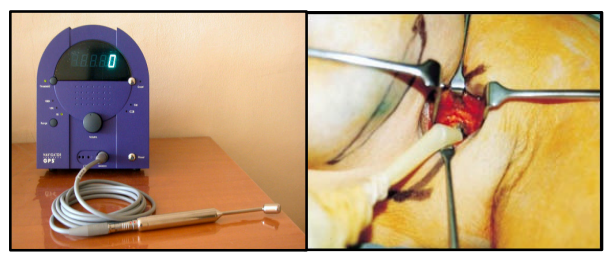

Gambar 2. Gamma Probe

intraoperasi menggunakan handheld gamma probe (kristal NalTL), hasil positif bila terjadi peningkatan aktivitas radioaktif $\rightarrow$ invivo 3:1, eksvivo 10:1 terhadap latar.

Metode blue dye dilakukan intraoperasi dengan menyuntikkan patent blue dye $2 \mathrm{ml}$ subkutan 4 kuadran peritumoral untuk menilai aluran limfatik dan limfonodi, hasil positif bila terdapat aktivitas pada limfonodi / blue node.

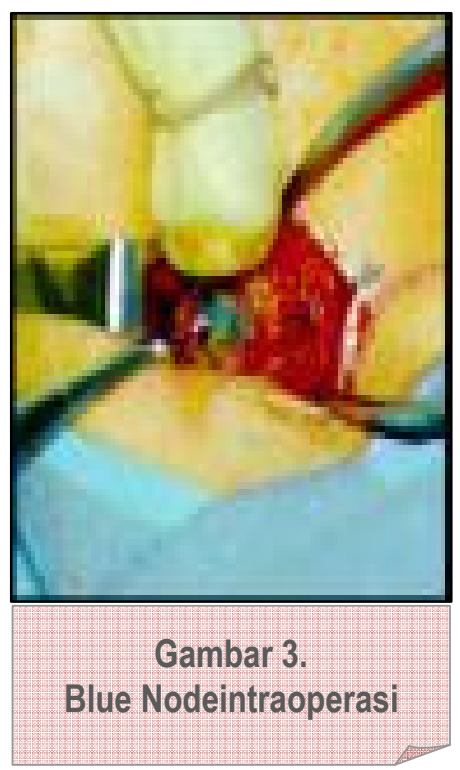


Setelah data terkumpul, dilakukan tabulasi hasil uji diagnostik dan pemeriksaan baku emas (histopatologi) untuk tiap pasien (dalam table $2 \times 2$ ), dengan tabel tersebut dihitung nilai akurasi, sensitifitas, dan spesifisitas.

\section{HASIL PENELITIAN}

Terdapat 14 pasien kanker payudara stadium dini di RS Ciptomangunkusumo Jakarta yang menjadi sampel penelitian. Dari 14 pasien tersebut didapatkan 163 limfonodi. Hasil penelitian dikelompokkan menjadi dua bagian, yaitu karakteristik subyek penelitian $(n=14)$ dan kapasitas deteksi limfonodi sentinel $(n=163)$.

\section{Karakteristik Subyek Penelitian}

Keseluruhan subyek penelitian ini perempuan. Hasil histopatologi tumor primer semuanya karsinoma duktal invasif, didapatkan emboli limfatik pada 71,4\% kasus.

\section{Tabel 1. Sebaran Karakteristik Demografik Subyek $(n=14)$}

\begin{tabular}{lcc}
\hline Karakteristik Demografik & Jumlah & Persen (\%) \\
\hline Kelompok usia & & \\
$\quad<45$ thn & 7 & 50.0 \\
$\quad>45$ thn & 7 & 50.0 \\
Paritas & & \\
Nulli para & 2 & 14.3 \\
Primi para & 4 & 28.6 \\
$\quad$ Multi para & 8 & 57.1 \\
Lama laktasi & & \\
Tak pernah & 4 & 28.6 \\
Sampai 6 bulan & 5 & 35.7 \\
Hampir 1 thn & 2 & 14.3 \\
Sampai 2 thn & 3 & 21.4 \\
Status menstruasi & & \\
Belum menopause & 5 & 35.7 \\
Sudah menopause & 9 & 64.3 \\
\hline
\end{tabular}

Tabel 2 . Sebaran Karakteristik Medik Subyek ( $n=14)$

\begin{tabular}{lcc}
\hline Karakteristik Medik & Jumlah & Persen (\%) \\
\hline Ukuran tumor & 1 & 7.1 \\
T1 & 8 & 57.1 \\
T2 & 5 & 35.7 \\
TX & & \\
Sisi payudara & 10 & 71.4 \\
$\quad$ Kanan & 4 & 28.6 \\
$\quad$ Kiri & & \\
Lokasi tumor & 10 & 71.4 \\
$\quad$ Lateral atas & 4 & 28.6 \\
$\quad$ Lateral bawah & &
\end{tabular}

Tabel 3. Nilai Rerata dan SD Variabel Subyek $(n=14)$

\begin{tabular}{lcccc}
\hline Variabel & Mean & SD & \multicolumn{2}{c}{$95 \% \mathrm{Cl}$} \\
\cline { 3 - 5 } & & & Low & High \\
\hline Umur subyek & 45.6 & 6.5 & 42.2 & 49.0 \\
Paritas & 1.5 & 0.9 & 1.0 & 2.0 \\
Jumlah limfonodi & 7.4 & 4.3 & 5.2 & 9.7 \\
\hline Kenyyy
\end{tabular}

Keterangan: Median paritas $=2.0$

Limfonodi $=7.0$

\section{Kapasitas Deteksi Limfonodi Sentinel}

Waktu injeksi radiokolloid sampai dilakukan operasi antara 4 jam sampai 24 jam dengan mean 9,6 jam, SD 7,5 jam, dan median 5 jam.

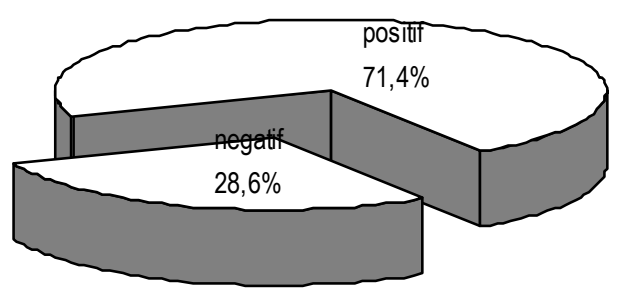

\section{Gambar 4.Deteksi Limfonodi dengan Metode Blue Dye} $(n=14)$

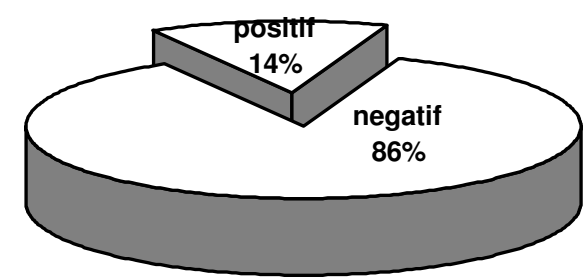

Gambar 5.Visualisasi Limfonodi Mammaria Interna $(n=14)$

Tabel 4. Hubungan antara Limfoskintigrafi dan PA $(n=163)$

\begin{tabular}{lccc}
\hline \multirow{2}{*}{ Limfoskintigrafi } & \multicolumn{2}{c}{ Hasil Histopatologi } & \multirow{2}{*}{ Jumlah } \\
\cline { 2 - 3 } & Positif & Negatif & \\
\hline Positif & 19 & 38 & 57 \\
Negatif & 2 & 104 & 106 \\
Jumlah & 21 & 142 & 163 \\
\hline Keterangan: Mc Nemar test & $p=0.000$ & & \\
\cline { 2 - 3 } Kappa $=0.37$ & $p=0.000$ & & \\
& &
\end{tabular}

Berdasar Tabel 4 dapat dilihat deteksi limfonodi sentinel dengan limfoskintigrafi preoperasi terhadap hasil histopatologi sebagai baku emas mempunyai sensitifitas $90,4 \%$, spesifisitas $73,2 \%$, akurasi $81,8 \%$, hasil negatif palsu $1,8 \%$. 
Tabel 5. Hubungan antara gamma probe dan PA ( $n=163)$

\begin{tabular}{|c|c|c|c|}
\hline \multirow{2}{*}{ Gamma probe } & \multicolumn{2}{|c|}{ Hasil Histopatologi } & \multirow{2}{*}{ Jumlah } \\
\hline & Positif & Negatif & \\
\hline Positif & 19 & 46 & 65 \\
\hline Negatif & 2 & 96 & 98 \\
\hline Jumlah & 21 & 142 & 163 \\
\hline $\begin{array}{r}\text { Keterangan: Mc Ne } \\
\text { Kappa }\end{array}$ & $\begin{array}{l}p=0.00 \\
p=0.00\end{array}$ & & \\
\hline
\end{tabular}

Tabel 5 memperlihatkan deteksi limfonodi sentinel dengan gamma probe terhadap hasil histopatologi sebagai baku emas mempunyai sensitivitas $90,4 \%$, spesifisitas $67,6 \%$, akurasi $79 \%$, hasil negatif palsu $2 \%$.

Tabel 6. Hubungan antara Metode Radiokolloid dengan PA $(n=163)$

\begin{tabular}{lccc}
\hline \multirow{2}{*}{ Metode radiokolloid } & \multicolumn{2}{c}{ Hasil Histopatologi } & \multirow{2}{*}{ Jumlah } \\
\cline { 2 - 3 } & Positif & Negatif & \\
\hline Positif & 19 & 33 & 52 \\
Negatif & 2 & 109 & 111 \\
Jumlah & 21 & 142 & 163 \\
\hline
\end{tabular}

Keterangan: Mc Nemar test $p=0.000$

$$
\text { Kappa }=0.56 \quad p=0.000
$$

Tabel 6 memperlihatkan deteksi limfonodi sentinel dengan metode radiokolloid (limfoskintigrafi dan gamma probe) terhadap hasil histopatologi sebagai baku emas mempunyai sensitivitas $90,4 \%$, spesifisitas $76,8 \%$, akurasi $83,6 \%$, hasil negatif palsu $1,8 \%$.

\section{DISKUSI}

Keseluruhan subyek penelitian perempuan, sesuai dengan literatur yang menyebutkan perempuan adalah merupakan faktor risiko utama kanker payudara. Perempuan mempunyai lebih banyak sel payudara yang secara konstan terpajan growth-promoting effects dari hormon estrogen dan progesteron, hal tersebut menyebabkan kejadian kanker payudara lebih sering daripada laki-laki. ${ }^{2}$ Angka kejadian kanker payudara pada perempuan 100 kali lebih banyak daripada laki-laki $(1,2)$.

Usia pasien termuda 39 tahun, tertua 53 tahun,usia rerata 45,6 tahun dengan SD 6,5 tahun. Data ini sesuai dengan literatur, yaitu risiko kanker payudara meningkat sesuai usia. Sekitar 18\% kanker payudara terdiagnosis pada usia 40 an, dan $77 \%$ terdiagnosis pada usia lebih dari 50 tahun $(1,2)$.

Jumlah yang sudah menopause lebih banyak daripada yang belum menopause. Status menopause menentukan prognosis kanker payudara, kemungkinan berulang lebih besar pada pasien premenopause $(1,2)$. Risiko kejadian kanker payudara meningkat sesuai lamanya siklus menstruasi total, perempuan yang awal periode menstru- asinya lambat atau mengalami menopause dini mempunyai risiko kejadian kanker payudara lebih rendah (2).

Subyek penelitian lebih banyak multipara. Data tersebut tidak sesuai dengan literatur yang menyebutkan risiko kanker payudara menurun dengan makin banyaknya anak yang dilahirkan (2). Kemungkinan hal ini disebabkan terlalu kecilnya sampel sehingga hasil penelitian tidak dapat dinilai secara umum.

Sebagian besar pasien menyusui anaknya, 21,4\% menyusui sampai 2 tahun. Data yang didapat tidak sesuai dengan data epidemiologi. Menyusui menurunkan risiko kejadian kanker payudara, terutama bila menyusui sampai 1,5 - 2 tahun. Lama menyusui mengurangi siklus menstruasi total sehingga mengurangi pajanan hormon estrogen dan progesteron pada sel payudara sebagai penyebab kanker payudara (2). Ketidaksesuaian hasil penelitian dengan data epidemiologis kemungkinan disebabkan terlalu kecilnya sampel.

Tumor primer kebanyakan ditemui di sisi kanan. Beberapa penelitian mendapatkan lokasi kanker payudara lebih banyak di sisi kiri, karena volume jaringan payudara kiri 2 - 3\% lebih banyak daripada kanan. Diketahui distribusi kanker payudara berhubungan dengan volume jaringan payudara. Penelitian lain justru mendapatkan kejadian kanker payudara lebih banyak di sisi kanan (2). Sesuai dengan penelitian ini, data epidemiologi menunjukkan lebih kurang $60 \%$ kanker payudara terletak di kwadran lateral atas (jam 9 sampai 12 mamma kanan dan jam 12 sampai 3 mamma kiri) (2).

Sebagian besar tumor berukuran $2-5 \mathrm{~cm}$ (stadium T2), kemungkinan disebabkan karena pada ukuran tersebut tumor dapat diraba sendiri sehingga pasien datang memeriksakan diri. Hanya satu pasien mempunyai ukuran tumor kurang dari $1 \mathrm{~cm}$ (stadium T1), dan 35,7\% pasien sudah dioperasi sebelumnya (stadium TX). Adanya jaringan parut bekas operasi menyebabkan gangguan sistim limfatik yang berakibat hasil negatif palsu pada pemeriksaan limfonodi $(9,10)$, tetapi hasil penelitian di St. Vincents hospital pada tahun 2000 menunjukkan adanya jaringan parut tidak berpengaruh terhadap aliran limfatik payudara karena drainase limfatik bisa melalui dermal atau subdermal (8).

Keseluruhan hasil histopatologi tumor primer adalah karsinoma duktal invasif yang memang merupakan tipe kanker payudara tersering. Diketahui $86 \%$ dari keseluruhan kanker payudara adalah karsinoma ductal invasif / infiltrating. Karsinoma duktal invasif dimulai dari duktus laktiferus dan meluas ke jaringan lemak payudara, karsinoma duktal invasif dapat bermetastasis melalui sistim limfatik dan aliran darah $(1,2)$.

Pada penelitian ini didapatkan emboli limfatik pada $71,4 \%$ pasien, emboli limfatik merupakan keadaan potensial metastasis. Secara teori emboli menyebabkan gangguan aliran limfatik yang berakibat hasil negatif palsu pada 
pemeriksaan limfonodi dengan metode radiokolloid dan blue dye. Hasil penelitian menunjukkan hasil negatif palsu $\leq 2 \%$ yang kemungkinan disebabkan emboli limfatik masih terbatas pada tumor primer (10).

Deteksi limfonodi sentinel dengan limfoskintigrafi preoperasi terhadap hasil histopatologi sebagai baku emas pada penelitian ini mempunyai sensitivitas yang tinggi $(90,4 \%)$ dan akurasi yang baik $(81,8 \%)$. Limfoskintigrafi preoperasi juga mempunyai negative predicted value yang tinggi $(98,1 \%)$ dengan hasil negatif palsu hanya $1,8 \%$. Data penelitian diatas sesuai dengan hasil penelitian Namwongprom dkk pada tahun 2005 yang mendapatkan akurasi $87,5 \%$ dengan hasil negatif palsu 12,5\% (11). Hasil tersebut membuktikan bahwa limfoskintigrafi preoperasi dapat memberikan informasi yang baik mengenai jumlah dan lokasi limfonodi sentinel serta memperlihatkan drainase limfatik tumor primer ke limfonodi regional yang diperlukan ahli bedah untuk melaksanakan prosedur SLNB.

Deteksi limfonodi sentinel dengan gamma probe intraoperasi terhadap hasil histopatologi sebagai baku emas mempunyai sensitivitas dan akurasi yang tinggi $(90,4 \%$ dan $79 \%$ ), gamma probe mempunyai negative predicted value $97,9 \%$ dengan hasil negatif palsu $2 \%$. Data tersebut sesuai dengan penelitian Dunnwald dkk tahun 1999 yang mendapatkan akurasi $85 \%$ dan hasil penelitian Kraft dkk tahun 2004 yang mendapatkan sensitivitas 88,5\% $(12,13)$. Hasil di atas memperlihatkan bahwa penggunaan gamma probe intraoperasi sangat penting untuk mempermudah identifikasi limfonodi sentinel. Dengan hand-held gamma probe ahli bedah akan lebih mudah menentukan lokasi limfonodi sentinel dan memastikan dengan tepat di incisi kulit akan dilakukan.

Lama waktu dari saat injeksi nannocolloid sampai dilakukan operasi pada penelitian ini bervariasi antara 4 sampai 24 jam, hasil ini sesuai dengan literatur bahwa waktu optimal menilai drainase limfatik dan radioactive node antara 2 sampai 24 jam (14).

Apabila deteksi limfonodi sentinel dilakukan dengan limfoskintigrafi preoperasi dan gamma probe intraoperasi maka kemampuan deteksi limfonodi sentinel lebih akurat (akurasi 83,6\%) dibanding bila hanya dilakukan salah satu saja. Hasil yang didapat sesuai dengan penelitian Schirrmeister dkk pada tahun 2002 yang mendapatkan akurasi metode radiokolloid (limfoskintigrafi dan gamma probe) bervariasi antara 69\% - 98\% (15). Data hasil penelitian ini menunjukkan sangat penting melakukan limfoskintigrafi preoperasi dan gamma probe intraoperasi untuk mendeteksi limfonodi sentinel pada kanker payudara stadium dini.

Berdasar analisis statistik, bila limfoskintigrafi preoperasi dan gamma probe intraoperasi keduanya dilakukan maka kesesuaian dengan hasil histopatologi akan lebih baik dibanding bila dilakukan hanya salah satu saja (nilai kappa
$0,56)$. Bila hanya dilakukan satu teknik untuk mendeteksi limfonodi sentinel, limfoskintigrafi preoperasi mempunyai kesesuaian yang lebih tinggi terhadap hasil histopatologi (nilai kappa 0,37 ) bila dibanding gamma probe intraoperasi (nilai kappa 0,31).

Limfoskintigrafi preoperasi dan gamma probe intraoperasi secara teori mempunyai akurasi yang setara dalam mendeteksi limfonodi sentinel. Akan tetapi banyak penelitian menyimpulkan limfoskintigrafi preoperasi mempunyai akurasi lebih tinggi dibanding gamma probe, demikian pula dengan hasil penelitian ini. Fenomena tersebut disebabkan pengaruh jarak waktu injeksi dan saat operasi, karena akumulasi radiofarmaka dipengaruhi waktu, limfoskintigrafi dapat memperlihatkan keseluruhan area drainase limfatik, lebih mudah mendeteksi kesalahan migrasi radiofarmaka, dapat menilai limfonodi sentinel yang letaknya berdekatan dengan tumor primer dan dapat membedakan beberapa limfonodi sentinel yang berdekatan. Gamma probe mempunyai kemungkinan malfungsi yang berakibat kegagalan mendeteksi limfonodi sentinel. Adanya tumpahan radiofarmaka ke kulit juga menyebabkan hasil positif palsu pada gamma probe yang tidak terjadi pada limfoskintigrafi $(13,16)$

Deteksi limfonodi sentinel dengan metode radiokolloid pada penelitian ini mempunyai hasil negatif palsu $1,8 \%$, sesuai dengan banyak penelitian lain yang rerata mempunyai hasil negatif palsu $<5 \%$. Sampai saat ini kemungkinan terbesar penyebab hasil negatif palsu adalah technical learning curve, diketahui hasil terbaik metode radiokolloid dalam mendeteksi limfonodi sentinel didapat setelah melakukan 60 - 80 kali pemeriksaan (11). Hasil negatif palsu juga disebabkan adanya skip metastase pada 2-5\% pasien.

Keberhasilan metode radiokolloid dalam mendeteksi limfonodi sentinel tergantung pada banyak faktor, antara lain:

1. Usia pasien. Makin tua kapasitas limfonodi menangkap radiokolloid menurun karena limfonodi diganti oleh lemak. Lamichhane (2003) melaporkan keberhasilan deteksi limfonodi menurun dan negatif palsu meningkat pada pasien berusia lebih dari 50 tahun (17). Menambah volume diluen dan dosis radioaktif akan meningkatkan tangkapan limfonodi.

2. Lokasi tumor primer, tumor yang terletak di medial mempunyai kemungkinan kegagalan yang tinggi karena adanya efek masking / overshadowing limfonodi mammaria interna dengan tempat injeksi.

3. Scar bekas operasi dapat menimbulkan gangguan drainase limfatik dan menyebabkan kegagalan mendeteksi limfonodi sentinel. Adanya jaringan parut bekas operasi menyebabkan tingginya negatif palsu, tapi penelitian di St. Vincents Hospital pada tahun 2000 tidak menunjukkan adanya hubungan scar bekas operasi dengan gangguan aliran limfatik (8). 
4. Ukuran payudara berhubungan dengan lamanya waktu lokalisasi limfonodi sentinel. Haigh dkk melaporkan bahwa makin besar payudara makin lama transit time (16)

5. Kemoterapi neoadjuvan menyebabkan gangguan drainase limfatik (6).

6. Teknik injeksi, injeksi intraparenkim peritumoral terbukti memberikan hasil lebih baik (16).

Menggunakan metode radiokolloid, didapatkan limfonodi sentinel adalah limfonodi mammaria interna pada $14 \%$ kasus, Shivers dkk juga mendapatkan 14\% pada penelitiannya, sementara Chan dkk hanya mendapatkan $5,5 \%$ (18). Sangat jarang ditemukan limfonodi sentinel adalah limfonodi mammaria interna, karena hanya 3\% aliran limfatik melalui limfonodi mammaria interna. Drainase ke limfonodi mammaria interna biasanya tampak bersamaan dengan drainase ke limfonodi axilla, yang hanya dapat dideteksi dengan injeksi isotop ke parenkim payudara (peritumoral), tidak dapat dideteksi dengan injeksi intradermal atau subareolar (5). Adanya obstruksi atau gangguan aliran limfatik yang menuju axilla juga menyebabkan limfonodi sentinel adalah limfonodi mammaria interna. Kemungkinan limfonodi sentinel adalah limfonodi mammaria interna lebih besar pada pasien dengan tumor primer di kwadran medial dan sentral. Tumor primer pada penelitian ini seperti penelitian Shivers dan Chan berada di kwadran lateral. Pasien dengan keterlibatan limfonodi mammaria interna mempunyai prognosis lebih buruk dan merupakan indikasi diberikan kemoterapi (18).
Pada penelitian ini, metode blue dye hanya menilai satu limfonodi tiap satu pasien $(n=14)$ dan tidak menilai keseluruhan limfonodi $(n=163)$ sehingga hasil yang didapat tidak mencerminkan hasil sebenarnya. Akurasi metode blue dye dalam juga tidak bisa dinilai. Dengan jumlah limfonodi 14, keberhasilan metode blue dye dalam mendeteksi limfonodi sentinel cukup baik $(71,4 \%$ positif). Kraft dkk pada tahun 2004 mendapatkan hasil positif 86,4\% (12). Juliano dkk mendapatkan akurasi metode blue dye $62-93 \%$ dengan positive predictive value dan negative predictive value $100 \%$ (8).

\section{KESIMPULAN DAN SARAN}

Metode radiokolloid (limfoskintigrafi preoperasi dan gamma probe intraoperasi) mempunyai akurasi dan kesesuaian yang tinggi dalam mendeteksi limfonodi sentinel pada kanker payudara stadium dini. Hal tersebut membuktikan metode radiokolloid dapat diaplikasikan sebagai dasar penggunaan SLNB di RSCM Jakarta. Penelitian ini juga mendapatkan $14 \%$ limfonodi sentinel merupakan limfonodi mammaria interna.

Perlu dilakukan penelitian lebih lanjut untuk mengetahui akurasi metode blue dye dalam mendeteksi limfonodi sentinel di RSCM Jakarta, karena data akurasi metode radiokolloid dan blue dye diperlukan sebagai dasar penggunaan metode SLNB. Penentuan tindakan diseksi axilla atau SLNB harus diputuskan intraoperasi, maka harus dilakukan penelitian lebih lanjut untuk menilai akurasi metode radiokolloid dan blue dye dengan hasil frozen section intraoperasi sebagai baku emas.

\section{DAFTAR KEPUSTAKAAN}

1. Gondhowiardjo S, Sekarutami SM, Poetiray EDC, et al. Breast Cancer Treatment: The Role of Surgery and Irradiation. In: The Multidisciplinary Cancer Management of Solid Tumors. Jakarta: Faculty of Medicine University of Indonesia $2004 ; 225-238$.

2. Cancer Reference Information. What are the Risk Factors for Breast Cancer. Available from: http://www.cancer.org. Last update: July 14. 2006.

3. Alazraki Np. Halkur RK. Using the sentinel node concept to stage breast cancer: Breast lymphoscintigraphy and intraoperative gamma probe sentinel node localization. In: Taillefer R, Khalkhali I, Waxman AD, Biersack HJ (editors) Radionuclide Imaging of the Breast. New York: Marcel Dekker Inc 1998; 397-416.

4. Kuehn T, Bembenek A, Decker T, et al. A Concept for the Clinical Implementation of Sentinel Lymph Node Biopsy in Patients with Breast Carcinoma with Special Regard to Quality Assurance. Cancer 2005; 103: 451-461.

5. Schwartz GF, Giuliano AE, Veronesi U, et al. Proceedings of the Consensus Conference of the Role of Sentinel Lymph Node Biopsy in Carcinoma of the Breast April 19-22, 2001, USA. Philadelphia, PA, The Breast 2002; 11:362-373.

6. Nieweg OE, Tanis PJ, Kroon BBR. The Definition of a Sentinel Node. Annals of Surgical Oncology 2001; 8: 518-541.

7. BNMS Draft Procedure Guidelines for Radionuclide Lymphoscintigraphy for Sentinel Node Localization in Breast Carcinoma. Available from: http://www.bnms.org.uk . Last updated: August 16, 2005.

8. Dayem HA. Sentinel node lymphoscintigraphy. In: IAEA Training Course on Scintimammography, SLN Detection and Intraoperative Surgical Probe Technology in the Management of Breast Cancer. New York: St Vincent Hospital and Medical Center. 2000.

9. Tanis PJ, Olmos RAV, Muller SH, Nieweg OE. Lymphatic Mapping in Patients with Breast Carcinoma: Reproducibility of Lymphoscintigraphic Results. Radiology 2003; 228: 546-551. 
10. Pandey M, Deo SVS, Maharajan R. Fallacies of Preoperative Lymphoscintigraphy in Detecting Sentinel Node in Breast Cancer. World Journal of Surgical Oncology 2005; 3: 1-4.

11. Namwongprom S, Boonyaprapa S, Ekmahachai M, et al. Breast Lymphoscintigraphy for Sentinel Node Identification in Breast Cancers with Clinically-Negative Axillary Nodes. Singapore Med J 2005; 46: 688-692.

12. Kraft O, Safarcik K, Stephen A. Our Experience with Sentinel Lymph Node Detection and Biopsy in Breast Cancer and Malignant Melanoma. Scripta Medica (BRNO) 2004; 77: 75 - 84.

13. Dunnwald LK, Mankoff DA, Byrd DR, et al. Technical Aspects of Sentinel Node Lymphoscintigraphy for Breast Cancer. Journal of Nuclear Medicine Technology 1999; 27: 106-111.

14. Sato K, Tamaki K, Shigekawa T, et al. Clinically Useful Detection Criteria for Sentinel Nodes in Patients with Breast Cancer Using A Radioisotope Technique. Jpn J Clin Oncol 2002; 32: 403-406.

15. Schirrmeister H, Kotzerke J, Buck AK, et al. Sentinel Biopsy in Breast Cancer: Result of a German Multicenter Study. Available from : http://interactive.snm.org/index.cfm . Last update: September 18, 2006.

16. Haigh PI, Hansen NM, Giuliano AE. Factors Affecting Sentinel Node Localization during Preoperative Breast Lymphoscintigraphy. Journal of Nuclear Medicine 2000; 41: 1682-1688.

17. Lamichhane N, Shen KW, Li Cl, et al. Sentinel Lymph Node Biopsy in Breast Cancer Patient after Overnight Migration of Radiolabelled Sulphur Colloid. Postgrad Med J 2004; 80: 546-550.

18. Chan VCY, Donohoe KJ. Association between Visualization of Internal Mammary Nodes on Breast Sentinel Node Scintigraphy and Diseased Axillary Nodes. Available from: http://www.jpnm.org. Last updated: September 26, 2006. 